\title{
Randomized Controlled Trial Examining Effects of Web-Based Information on Patient Satisfaction and Image Quality in ${ }^{18}$ F-FDG PET/CT Examinations
}

\author{
Camilla Andersson ${ }^{1}$, Carlos Trampal Pulido ${ }^{1}$, Håkan Ahlström ${ }^{1}$, and Birgitta Johansson ${ }^{2}$ \\ ${ }^{1}$ Department of Surgical Sciences, Uppsala University, Uppsala, Sweden; and ${ }^{2}$ Department of Immunology, Genetics, and Pathology, \\ Uppsala University, Uppsala, Sweden
}

Our aim was to compare the effect that having access, versus not having access, to web-based patient information on ${ }^{18} \mathrm{~F}-\mathrm{FDG}$ $\mathrm{PET} / \mathrm{CT}$ has on image quality and on patient satisfaction with their care during and knowledge about the examination, as well as to explore whether patients utilized and were satisfied with the web-based information. Methods: We recruited 148 patients between October 2015 and December 2016 and randomly assigned them to a standard-care group or an intervention group. Both groups received standard information about the ${ }^{18} \mathrm{~F}-\mathrm{FDG}$ PET/CT examination, but the intervention group also received access to web-based information. A questionnaire was used to evaluate patient satisfaction with, knowledge about, and discomfort during the examination, and a masked assessment of image quality was conducted. Results: Overall satisfaction was high in both groups. The lowest satisfaction was with information about how the patients would receive the results of the examination. More patients in the intervention group than in the standard-care group knew how the ${ }^{18} \mathrm{~F}-\mathrm{FDG}$ PET/CT examination would be conducted. Descriptive data suggest that image quality was slightly better in the intervention group than in the standard-care group, but none of the outcomes significantly differed between the groups. However, several obstacles were encountered during recruitment that led to insufficient power to detect differences. Also, only 54 of 75 patients $(72 \%)$ in the intervention group utilized the web-based information. However, those who did utilize the information were satisfied with it and found it helpful. Conclusion: The effects of web-based information need to be investigated in a larger sample of patients. Having access to improved information before undergoing ${ }^{18} \mathrm{~F}-\mathrm{FDG}$ PET/CT may help patients prepare for and undergo the examination. It may also improve image quality. However, this possibility needs to be investigated using image quality as the primary outcome. The results may be used to improve patient information and care and thereby optimize the ${ }^{18} \mathrm{~F}-\mathrm{FDG} \mathrm{PET} / \mathrm{CT}$ procedure.

Key Words: ${ }^{18} \mathrm{~F}-\mathrm{FDG}$ PET/CT; web-based information; image quality; satisfaction; randomized controlled trial

J Nucl Med Technol 2019; 47:39-46

DOI: 10.2967/jnmt.118.213116

Received Apr. 16, 2018; revision accepted Jul. 21, 2018.

For correspondence or reprints contact: Camilla Andersson, Department of Nuclear Medicine, Uppsala University Hospital, SE-751 85 Uppsala, Sweden. E-mail: camilla.andersson@radiol.uu.se

Published online Aug. 3, 2018.

COPYRIGHT (C) 2019 by the Society of Nuclear Medicine and Molecular Imaging.
$\mathbf{P}$ ${ }^{18} \mathrm{~F}-\mathrm{FDG}$ is used in oncology imaging and has proven valuable for diagnosis, staging, and evaluation of therapy response (1-3). Oncologic patients who undergo ${ }^{18} \mathrm{~F}-\mathrm{FDG}$ PET/CT may experience discomfort during time spent in the PET/ CT scanner (4), anxiety before the procedure (5), or anxiety after the procedure because of fears concerning the results (6).

Patients increasingly seek information on the Internet about planned imaging examinations but may become misinformed if they choose websites whose information is incorrect $(7,8)$. Development of web-based information by a nuclear medicine department may be one way to provide patients with accurate information tailored to their needs. In one study, patients who received access to web-based educational material about mammography had more positive perceptions about and greater intention to undergo mammography than patients who received standard, non-webbased information (9). The value of web-based information in conjunction with PET/CT has still not been explored.

${ }^{18}$ F-FDG PET/CT requires that patients follow instructions on what to do before the examination, as well as instructions from the nursing staff during the examination, to optimize tracer uptake in tumor tissue and reduce uptake in normal tissue (bladder, skeletal muscle, brown fat) and to keep the radiation dose to the patient as low as possible. Tracer uptake in normal tissue makes it difficult to interpret the images and thereby may delay diagnosis of cancer (1).

Our previous studies on oncology patients undergoing ${ }^{18}$ F-FDG (4) and ${ }^{18}$ F-fluoride (10) PET/CT found that many patients did not know what a PET/CT examination was beforehand. Most were satisfied with the care provided, but there was room for improvement, especially with regard to information provided before the examination and communication during the examination $(4,10)$. Improved information may improve patients' understanding of the procedure and in turn improve image quality and diagnosis.

Our aim was to compare the effect that having access, versus not having access, to web-based patient information on ${ }^{18} \mathrm{~F}$-FDG PET/CT has on image quality and on patient satisfaction with their care during and knowledge about the 
examination, as well as to explore whether patients utilized and were satisfied with the web-based information.

\section{MATERIALS AND METHODS}

\section{Patients}

All patients who were referred for an ${ }^{18} \mathrm{~F}-\mathrm{FDG}$ PET/CT examination with or without iodine contrast between October 2015 and December 2016 were assessed for eligibility. The inclusion criterion was a referral for a standard whole-body ${ }^{18} \mathrm{~F}$-FDG PET/CT examination to investigate known or suspected malignancy. Patients were excluded if they had ever undergone PET/CT previously, could not communicate in Swedish, were younger than $18 \mathrm{y}$, or were scheduled to undergo the examination less than $5 \mathrm{~d}$ after being notified of the date. In total, 2,275 patients were excluded and 75 of the included patients could not be reached by telephone (Fig. 1). The most frequent reason that patients gave for declining to participate was no access to the Internet $(n=97)$ or distress due to their cancer diagnosis. The study was approved by the ethics review board in Uppsala, Sweden (approvals 2014/549 and 2014/ 549/1), and all participants gave written informed consent.

\section{Power Analysis and Randomization}

The primary outcome was overall satisfaction, being the sum of 8 questions on patient satisfaction used in our previous study (4). It was estimated that enrolling 100 patients in each group would provide $80 \%$ power to detect a mean difference of 1.8 (SD, 4.8). The randomization was done according to Efron's biased coin design (11) by a person not belonging to the research group.

\section{Procedure}

Eligible patients received written information on the study together with their notice of the examination date. After a few days, the first author called the patient by telephone to talk about the study. After randomization to the intervention or standard-care group, the patients received an e-mail telling them which group they were in and how to contact the first author if they had questions. Patients in the intervention group received access to the web-based information by logging into a patient portal. After the

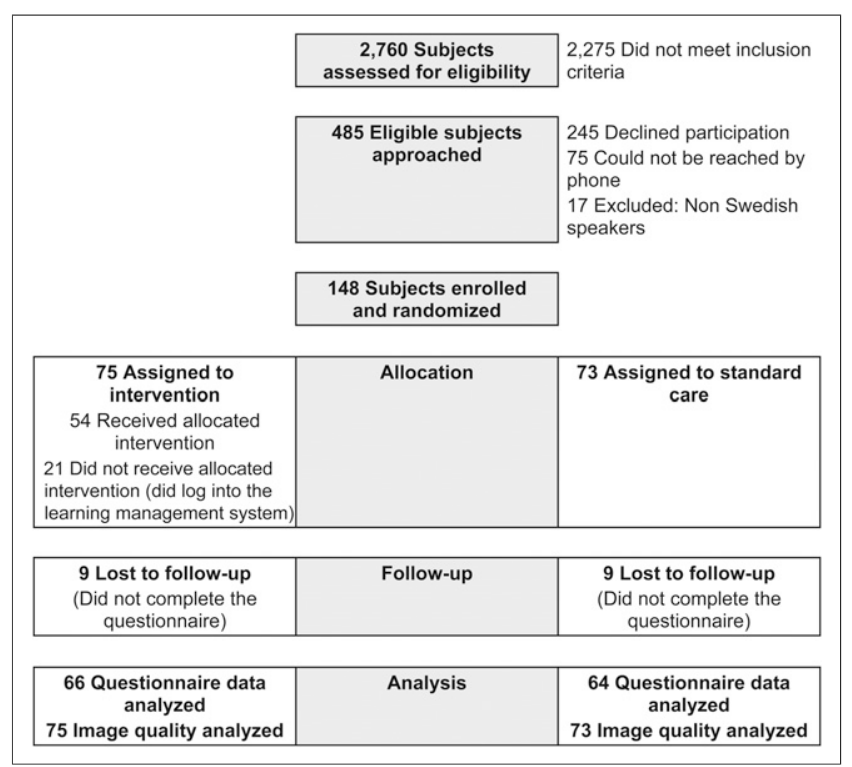

FIGURE 1. Participant flow.
${ }^{18}$ F-FDG PET/CT examination, a questionnaire was mailed to all participants along with a stamped, self-addressed envelope. If there was no reply after $2 \mathrm{wk}$, a reminder and another copy of the questionnaire were mailed. It was decided to terminate the enrollment in December 2016, before 200 patients had been included.

\section{Web-Based Information}

The web-based patient information was delivered within a learning management system and consisted of an 8-min slideshow featuring photos, pictures, and a voiceover explaining how the ${ }^{18} \mathrm{~F}-$ FDG PET/CT examination is performed, why patients need to follow preexamination instructions and instructions during the procedure, what happens after the examination, and how patients receive the results. The manuscript could be read online and downloaded as a pdf. The learning management system also included answers to frequently asked questions. All material was designed by the first author in collaboration with the last author. Facts were checked by a radiologist and by a physicist with extensive experience in PET/CT. Five patients who were not included in the study were asked to review the web-based information after undergoing ${ }^{18} \mathrm{~F}-\mathrm{FDG}$ PET/CT. Minor corrections were made on the basis of the feedback they provided in a think-aloud session to explore the face validity of the project-specific questions (12).

\section{Standard Care}

Both groups received 2 pages of information about the ${ }^{18} \mathrm{~F}-\mathrm{FDG}$ PET/CT examination simultaneously with the time and location of their appointment.

\section{F-FDG PET/CT Examination}

The patients were told to fast for $6 \mathrm{~h}$ before the appointment; to drink $0.5-1 \mathrm{~L}$ of tap water before the appointment; and to remain silent, warm, and at rest when receiving the injection $(4 \mathrm{MBq}$ of ${ }^{18} \mathrm{~F}-\mathrm{FDG} / \mathrm{kg}$ of body weight intravenously) and for $1 \mathrm{~h}$ afterward. They were also told to drink $0.5 \mathrm{~L}$ of tap water during the last $30 \mathrm{~min}$ of the uptake phase and to void the bladder immediately before entering the PET/CT scanner (a Discovery VCT [GE Healthcare] with a 64-slice CT component). The examination began with a low-dose CT scan for attenuation correction, followed by a PET acquisition from the middle of the thigh to the jaw or the top of the skull. The acquisition time was 3 min per bed position, and 3-dimensional mode was used. Enhanced or nonenhanced diagnostic CT was then performed over the same region as the PET acquisition. The total scanning time was 25-30 min, during which the patients remained in the same position with the arms elevated over the head.

\section{Data Collection}

Medical and Demographic Data. Information about age, sex, and diagnosis was collected from the referral source, whereas information about civil status, level of education, occupation, and income was received from the patient.

Satisfaction. Overall satisfaction constituted the sum of 8 questions whose answers were scored from 1 (not at all satisfied) to 5 (satisfied to a very high degree). Three of the questions were study-specific and concerned satisfaction with information provided about the examination and interaction with the nursing staff. The other 5 questions were from a patient experience questionnaire (13) and concerned interaction with the nursing staff, communication, professional skills, and an overall impression about the hospital. The 8 questions were also analyzed as single variables along with an additional question concerning satisfaction 
with information on how the patients would receive the examination results.

Knowledge and Discomfort. Five study-specific questions explored patients' knowledge about the ${ }^{18}$ F-FDG PET/CT examination, how exhausting the examination was, how trapped they felt during the examination, and to what extent the examination corresponded to their expectations. They could also add free-text comments on their experiences during the examination.

Image Quality. The image quality of examinations was assessed by a specialist in nuclear medicine, who was masked to the randomization. A project-specific form with 2- or 3-point scales was developed to rate physiologic uptake in the larynx (vocal cords), the amount of bladder activity, the presence of activated brown fat, motion artifacts, the degree of muscle uptake, overall diagnostic accuracy, and whether the uptake indicated benign or malignant findings.
Utilization of and Satisfaction with the Web-Based Information. Information about which patients used the web-based information and their number of log-ins was retrieved from the learning management system. The patients in the intervention group received 15 questions on the usability of the web-based information, their satisfaction with it, and whether it helped them prepare for and undergo the ${ }^{18}$ F-FDG PET/CT examination.

\section{Data Analysis}

Data were analyzed using the Statistical Package for Social Sciences, version 24.0. Analyses were done by intention to treat. Since overall satisfaction was reasonably normally distributed, with similar means and medians in the two groups, a $t$ test was used to analyze mean differences in overall satisfaction. Most single variables were skewed and analyzed with the Mann-Whitney $U$ test

TABLE 1

Medical and Demographic Characteristics

\begin{tabular}{|c|c|c|c|}
\hline \multirow[b]{2}{*}{ Characteristic } & \multirow[b]{2}{*}{ Standard care $(n=73)$} & \multicolumn{2}{|c|}{ Intervention $(n=75)$} \\
\hline & & Utilized intervention $(n=54)$ & Did not utilize intervention $(n=21)$ \\
\hline \multicolumn{4}{|l|}{ Age $(y)$} \\
\hline Mean & 63 & 64 & 64 \\
\hline Range & $24-84$ & $26-80$ & $30-80$ \\
\hline \multicolumn{4}{|c|}{ Known or suspected cancer diagnosis } \\
\hline Lung cancer & $25(34)$ & $23(43)$ & $7(33)$ \\
\hline Colorectal cancer & $5(7)$ & $15(28)$ & $2(10)$ \\
\hline Ovarian cancer & $9(12)$ & $5(9)$ & $4(19)$ \\
\hline Other & $34(47)$ & $11(20)$ & $8(38)$ \\
\hline \multicolumn{4}{|l|}{ Sex } \\
\hline Male & $34(47)$ & $30(56)$ & $10(48)$ \\
\hline Female & $39(53)$ & $24(44)$ & $11(52)$ \\
\hline \multicolumn{4}{|l|}{ Civil status* } \\
\hline Married/cohabitant & $53(83)$ & $37(69)$ & $11(52)$ \\
\hline Single & $8(13)$ & $8(15)$ & $3(14)$ \\
\hline Widow/widower & $1(2)$ & $3(6)$ & $3(14)$ \\
\hline Living apart & $2(3)$ & $1(2)$ & 0 \\
\hline \multicolumn{4}{|l|}{ Education ${ }^{*}$} \\
\hline Compulsory school & $13(20)$ & $7(13)$ & $7(33)$ \\
\hline Upper secondary school & $29(45)$ & $21(39)$ & $6(29)$ \\
\hline University, 0-4 y & $15(23)$ & $11(20)$ & $3(14)$ \\
\hline University, $>4$ y & $7(11)$ & $9(17)$ & $1(5)$ \\
\hline \multicolumn{4}{|l|}{ Occupation ${ }^{\star}$} \\
\hline Working & $19(30)$ & $13(24)$ & $5(24)$ \\
\hline Sick leave & $6(9)$ & $2(4)$ & $3(14)$ \\
\hline Studies & $1(2)$ & $1(2)$ & 0 \\
\hline Home work & $4(6)$ & $0(0)$ & 0 \\
\hline Unemployed & $2(3)$ & $1(2)$ & 0 \\
\hline Other & $32(50)$ & $31(57)$ & $9(43)$ \\
\hline \multicolumn{4}{|c|}{ Monthly income (Swedish kronas)* } \\
\hline $0-4,999$ & $1(2)$ & $1(2)$ & 0 \\
\hline $5,000-9,999$ & $2(3)$ & $1(2)$ & $2(10)$ \\
\hline $10,000-14,999$ & $12(19)$ & $12(22)$ & $6(29)$ \\
\hline $15,000-19,999$ & $19(30)$ & $11(20)$ & $3(14)$ \\
\hline $20,000-24,999$ & $5(8)$ & $9(17)$ & $2(10)$ \\
\hline $25,000-29,999$ & $12(19)$ & $4(7)$ & $2(10)$ \\
\hline $30,000-34,999$ & $5(8)$ & $2(4)$ & 0 \\
\hline$>35,000$ & $7(11)$ & $8(15)$ & $2(10)$ \\
\hline PET/CT with contrast & $62(85)$ & $42(78)$ & $17(81)$ \\
\hline
\end{tabular}

${ }^{*}$ Did not complete questionnaire: 9 standard-care group; 5 intervention group, utilized intervention; 4 intervention group, did not utilize intervention.

Data are number of patients followed by percentage in parentheses, except for age. 
with regard to differences between the groups. The $\chi^{2}$ test was used to analyze differences in image quality. Free-text comments were categorized into groups with similar answers. A per-protocol analysis was also conducted, comparing those who utilized the intervention with those in the standard-care group. Differences in demographic data were analyzed with the Mann-Whitney $U$ test or the $\chi^{2}$ test.

\section{RESULTS}

\section{Patients}

Of 393 approached patients, $148(38 \%)$ agreed to participate, and the response rate was $88 \%$ (Fig. 1). The most common diagnosis was lung cancer (Table 1). Patients who agreed to participate were younger than those who declined (mean age, 64 vs. $69 \mathrm{y}, P=0.000$ ). The distributions of diagnoses differed between the groups $\left(\chi^{2}=11.2\right.$,
$P=0.01)$. Fifty-nine patients in the intervention group and 62 in the standard-care group received contrast during the ${ }^{18} \mathrm{~F}$-FDG PET/CT examination. Twenty-one patients (28\%), referred to as nonusers, did not log into the learning management system. Nonusers were less educated than users (Mann-Whitney $U$ test, $P=0.032$ ). No other differences in demographic data were found.

\section{Satisfaction}

The overall satisfaction was high in both groups (intervention group, mean $=28.4$; standard-care group, mean $=28.8$ ) (Table 2). Also, satisfaction with all single satisfaction items was high, with only small, statistically nonsignificant differences between groups (Table 2). The lowest satisfaction scores concerned how patients would be notified of their examination results (Table 2).

TABLE 2

Patient Satisfaction with ${ }^{18} \mathrm{~F}-\mathrm{FDG}$ PET/CT Examination

\begin{tabular}{|c|c|c|c|c|c|}
\hline Question & \multicolumn{5}{|c|}{ Not at all To low degree To some degree To high degree To very high degree } \\
\hline \multicolumn{6}{|c|}{$\begin{array}{l}\text { 1. Were you satisfied with the information you } \\
\text { received before the examination? }\end{array}$} \\
\hline Intervention & $1(2)$ & $4(6)$ & $15(23)$ & $32(49)$ & $14(21)$ \\
\hline Standard care & $1(2)$ & $2(3)$ & $18(28)$ & $33(52)$ & $10(16)$ \\
\hline \multicolumn{6}{|c|}{$\begin{array}{l}\text { 2. Were you satisfied with the information you } \\
\text { received when you came to the examination? }\end{array}$} \\
\hline Intervention & 0 & $3(5)$ & $8(12)$ & $29(44)$ & $25(38)$ \\
\hline Standard care & $1(2)$ & $1(2)$ & $8(13)$ & $34(53)$ & $20(31)$ \\
\hline \multicolumn{6}{|c|}{$\begin{array}{l}\text { 3. Were you satisfied with your interaction with } \\
\text { the nursing staff during the examination? }\end{array}$} \\
\hline Intervention & $1(2)$ & 0 & $8(12)$ & $27(41)$ & $30(46)$ \\
\hline Standard care & $1(2)$ & $2(3)$ & $3(5)$ & 25 (39) & $33(52)$ \\
\hline \multicolumn{6}{|c|}{$\begin{array}{l}\text { 4. Did the nursing staff communicate in an } \\
\text { understandable way? }\end{array}$} \\
\hline Intervention & 0 & 0 & $7(11)$ & $28(42)$ & $31(47)$ \\
\hline Standard care & 0 & $1(2)$ & $3(5)$ & $29(45)$ & 31 (48) \\
\hline \multicolumn{6}{|l|}{$\begin{array}{l}\text { 5. Did the nursing staff convey a } \\
\text { caring attitude? }\end{array}$} \\
\hline Intervention & $1(2)$ & $1(2)$ & 7 (11) & $23(35)$ & 34 (52) \\
\hline Standard care & $1(2)$ & $1(2)$ & $3(5)$ & $28(44)$ & 31 (48) \\
\hline \multicolumn{6}{|c|}{$\begin{array}{l}\text { 6. Did you feel confident in the professional } \\
\text { skills of the nursing staff? }\end{array}$} \\
\hline Intervention & 0 & 0 & $4(6)$ & $27(41)$ & 34 (52) \\
\hline Standard care & 0 & 0 & $1(2)$ & 25 (39) & 38 (59) \\
\hline \multicolumn{6}{|c|}{$\begin{array}{l}\text { 7. Did the nursing staff have adequate time } \\
\text { for you when you needed them? }\end{array}$} \\
\hline Intervention & 0 & $3(5)$ & $9(14)$ & $24(36)$ & $15(23)$ \\
\hline Standard care & 0 & $1(2)$ & $5(8)$ & $29(45)$ & $29(45)$ \\
\hline \multicolumn{6}{|c|}{$\begin{array}{l}\text { 8. Are you satisfied with how you will be } \\
\text { notified about the examination results? }\end{array}$} \\
\hline Intervention & $4(6)$ & $6(9)$ & $16(24)$ & $24(36)$ & $15(23)$ \\
\hline Standard care & $2(3)$ & 9 (14) & 11 (17) & $26(41)$ & $16(25)$ \\
\hline \multicolumn{6}{|c|}{$\begin{array}{l}\text { 9. Did you get the impression that the work } \\
\text { of the hospital was well organized? }\end{array}$} \\
\hline Intervention & $1(2)$ & $5(8)$ & $5(8)$ & $36(55)$ & $18(27)$ \\
\hline Standard care & $1(2)$ & 0 & $10(16)$ & $30(47)$ & $22(34)$ \\
\hline
\end{tabular}

Intervention group, $n=66$; standard-care group, $n=64$.

Data are number of patients followed by percentage in parentheses. Overall satisfaction (sum of questions 1-7 and 9) had a mean, SD, median, minimum, and maximum of 28.4, 5.3, 28.0, 16.0, and 36.0, respectively, for the intervention group and 28.8, 4.9, 28.0, 15.0, and 36.0 , respectively, for the standard-care group. 


\section{Knowledge and Discomfort}

More patients in the intervention group (38\%) than in the standard-care group (16\%) knew "quite a lot" or "very much" about the procedure before undergoing it (Table 3). Forty percent of the intervention group and $45 \%$ of the standardcare group thought the examination was exhausting, to varying degrees (Table 2). Also, $41 \%$ of the intervention group and $29 \%$ of the standard-care group felt trapped during the examination (Table 3). None of these differences were statistically significant. Free-text comments revealed that the most positive experiences were the care provided by the nursing staff during the procedure $(n=59)$ and its shorter-than-expected total duration $(n=27)$. The most negative experiences were the time spent in the scanner, the need to keep the body position fixed $(n=38)$, and the wait for the results $(n=9)$.

\section{Image-Quality Assessment}

Overall diagnostic accuracy was high for all patients (Table 4). No statistically significant difference was found between the groups. The proportion of studies with a defect in quality was higher in the standard-care group than in the intervention group. These defects regarded physical uptake in the larynx (60\% vs. $51 \%)$, abnormal bladder activity ( $22 \%$ vs. $15 \%)$, activated brown fat (5\% vs. $0 \%$ ), and motion artifacts $(12 \%$ vs. $8 \%)$. With regard to muscle uptake, the proportion with a defect in quality was slightly higher in the intervention group than in the standard-care group (24\% vs.
$22 \%)$. Sixty-seven percent of patients in the intervention group and $56 \%$ in the standard-care group had malignant uptake.

\section{Per-Protocol Analyses}

The comparison of patients who utilized the web-based information with patients in the standard-care group found no significant differences in patient satisfaction, knowledge, discomfort, or image quality.

\section{Use of and Satisfaction with Web-Based Information}

Fifty-four patients (72\%) in the intervention group utilized the web-based information, with the number of log-ins ranging from 1 to 6 . They thought that navigation and use of the web portal were "very easy" (33\%) or "pretty easy" (59\%) and that the ease of understanding the content was "very high" (12\%) or "high" (71\%) (Table 5). Many (88\%) thought they got access to the web-based information right on time. With regard to preparing for the examination, $14 \%$ had "much" and 53\% "quite a lot" of use for the information; with regard to undergoing the examination, $16 \%$ had "much" and 57\% "quite a lot" of use for the information; and with regard to reduced worry about the examination, $37 \%$ had "quite a lot" and $8 \%$ "much" use for the information (Fig. 2). A majority were "mostly" (55\%) or "very" (31\%) satisfied with the web-based information and would "yes, absolutely" (57\%) or "yes, I think so" (41\%) recommend it to another patient undergoing ${ }^{18} \mathrm{~F}-\mathrm{FDG}$ PET/CT (Table 5).

TABLE 3

Patients' Knowledge About and Discomfort During ${ }^{18}$ F-FDG PET/CT Examination

\begin{tabular}{|c|c|c|}
\hline Question & Intervention $(n=66)$ & Standard care $(n=64)$ \\
\hline \multicolumn{3}{|c|}{ Did you know beforehand what an ${ }^{18} \mathrm{~F}-\mathrm{FDG}$ PET examination was? } \\
\hline Not at all & $25(38)$ & $23(36)$ \\
\hline Some & $17(26)$ & $26(41)$ \\
\hline Quite a lot & $19(29)$ & $10(16)$ \\
\hline I knew very much & $5(8)$ & $3(5)$ \\
\hline \multicolumn{3}{|c|}{ Did you know beforehand how an ${ }^{18} \mathrm{~F}-\mathrm{FDG}$ PET examination was conducted? } \\
\hline Not at all & $22(33)$ & $28(44)$ \\
\hline Some & $19(29)$ & $24(38)$ \\
\hline Quite a lot & $20(30)$ & $9(14)$ \\
\hline I knew very much & $5(8)$ & $1(2)$ \\
\hline \multicolumn{3}{|l|}{ Did you feel trapped during the examination? } \\
\hline Not at all & $39(59)$ & $45(70)$ \\
\hline Some & $22(33)$ & $12(19)$ \\
\hline Much & $4(6)$ & $5(8)$ \\
\hline Very much & $1(2)$ & $1(2)$ \\
\hline \multicolumn{3}{|l|}{ How exhausting was the examination? } \\
\hline Not at all & $39(59)$ & $35(55)$ \\
\hline Some & $13(20)$ & $20(31)$ \\
\hline Much & $12(18)$ & $7(11)$ \\
\hline Very much & $1(2)$ & $2(3)$ \\
\hline \multicolumn{3}{|l|}{ Was the examination as you expected it to be? } \\
\hline Much easier & $11(17)$ & $5(8)$ \\
\hline A bit easier & $13(20)$ & $17(27)$ \\
\hline Just as I expected & $36(55)$ & $36(56)$ \\
\hline A bit worse & $6(9)$ & $5(8)$ \\
\hline Much worse & 0 & $1(2)$ \\
\hline
\end{tabular}


TABLE 4

Results of Image-Quality Assessment of ${ }^{18}$ F-FDG PET/CT Examination

\begin{tabular}{|c|c|c|}
\hline $\begin{array}{l}\text { Image-quality } \\
\text { parameter }\end{array}$ & $\begin{array}{l}\text { Intervention } \\
\quad(n=75)\end{array}$ & $\begin{array}{c}\text { Standard } \\
\text { care }(n=73)\end{array}$ \\
\hline \multicolumn{3}{|l|}{$\begin{array}{l}\text { Physiologic uptake } \\
\text { in larynx }\end{array}$} \\
\hline None & $37(49)$ & $29(40)$ \\
\hline Some & 29 (39) & $36(49)$ \\
\hline Much & $9(12)$ & $8(11)$ \\
\hline \multicolumn{3}{|l|}{$\begin{array}{l}\text { Amount of bladder } \\
\text { activity }\end{array}$} \\
\hline Normal & $64(85)$ & $57(78)$ \\
\hline Abnormal & $11(15)$ & $16(22)$ \\
\hline \multicolumn{3}{|c|}{$\begin{array}{l}\text { Presence of } \\
\text { activated brown fat }\end{array}$} \\
\hline None & 75 (100) & $69(95)$ \\
\hline Some & 0 & $4(5)$ \\
\hline Much & 0 & 0 \\
\hline \multicolumn{3}{|l|}{ Motion artifacts } \\
\hline None & $69(92)$ & $64(88)$ \\
\hline Some & $6(8)$ & $9(12)$ \\
\hline Much & 0 & 0 \\
\hline \multicolumn{3}{|l|}{$\begin{array}{l}\text { Degree of muscle } \\
\text { uptake }\end{array}$} \\
\hline None & $57(76)$ & $57(78)$ \\
\hline Some & $17(23)$ & $15(21)$ \\
\hline Much & $1(1)$ & $1(1)$ \\
\hline \multicolumn{3}{|l|}{$\begin{array}{l}\text { Overall diagnostic } \\
\text { accuracy }\end{array}$} \\
\hline Good & 75 (100) & $73(100)$ \\
\hline Intermediate & 0 & 0 \\
\hline Poor & 0 & 0 \\
\hline \multicolumn{3}{|l|}{ Variant of uptake } \\
\hline Benign & $25(33)$ & $32(44)$ \\
\hline Malignant & $50(67)$ & 41 (56) \\
\hline
\end{tabular}

Data are number of patients followed by percentage in parentheses.

\section{DISCUSSION}

To our knowledge, this is the first study investigating the effects of web-based information on patient satisfaction, patient knowledge, and image quality in ${ }^{18} \mathrm{~F}-\mathrm{FDG}$ PET/CT. Image quality seemed to be slightly better in the intervention group than in the standard-care group, and users of the web-based information experienced various benefits from it, but there were no statistically significant differences between the groups and satisfaction with the care provided by the nursing staff was high in both groups. A serious limitation is the lack of power to detect a difference in the primary outcome-overall satisfaction with care-because of the premature termination of recruitment. Also, more than a quarter of the patients in the intervention group did not utilize the intervention, further limiting the statistical power and indicating the need for more convenient access to the web-based information.

Similar to our findings, another study found no statistically significant difference between patients who received standard information before colposcopy and those who additionally received video information (14). However, patient satisfaction was high and anxiety reduced in those who saw the video (14). Also, the high satisfaction with the nursing staff in the present study is similar to the findings of other studies on patients undergoing ${ }^{18} \mathrm{~F}$-FDG PET/ CT (4-6). The lowest satisfaction concerned how the patients would receive the results of the examination. This finding is similar to another study revealing that patients may experience anxiety during ${ }^{18} \mathrm{~F}-\mathrm{FDG} \mathrm{PET} / \mathrm{CT}$, mainly because of fear of the results (6), and indicates the importance of having the nurses who execute the examination make sure patients understand how they will receive the results. Some patients experienced discomfort during the ${ }^{18}$ F-FDG PET/CT examination, especially regarding the time spent in the scanner and the need to maintain a fixed body position, as is consistent with our previous findings $(4,10)$. We therefore suggest that various ways be found to improve patient comfort when in the scanner.

The image-quality assessment revealed a high level of diagnostic accuracy. This is similar to previous findings indicating high image quality both in patients who experienced pain or discomfort during an ${ }^{18} \mathrm{~F}$-fluoride PET/CT examination and in those who did not (10). There were slightly more image-quality defects in the standard-care group than in the intervention group. Users in the intervention group reported that the web-based information helped them prepare for and undergo the ${ }^{18} \mathrm{~F}-\mathrm{FDG}$ PET/CT examination, potentially explaining the lower frequency of defects in the intervention group. This finding is somewhat similar to that of Törnqvist et al. (15), who found that extended written patient information on an MRI examination decreased the presence of image artifacts (15). It has also been found that the use of web-based information may increase a patient's intention to undergo a diagnostic examination and adherence to undergoing it (9). These studies indicate the value of providing extended information to patients before they undergo various diagnostic examinations. However, further investigation is needed in properly designed trials using image quality as the primary outcome. The fact that high image quality was found despite the presence of some defects in quality suggests that patient preparation and adherence to instructions before ${ }^{18} \mathrm{~F}-\mathrm{FDG}$ PET/CT are relevant, as stated in the European Association of Nuclear Medicine guidelines (1), and should be investigated in larger populations and, if possible, revised to reduce patient burden before and during the examination.

The 21 patients who did not utilize the web-based information were less educated than the users and thus might not have been as familiar with computers and the Internet. Likewise, Katz et al. (16) found that level of education was the best predictor that cancer patients will use the Internet to research their condition. The high mean age in the present sample may be another reason for the proportion of nonusers. However, a recent study found that older adults may use the Internet to improve their health-related knowledge (17), indicating that web-based information might be accessed 
TABLE 5

Use and Satisfaction with Web-Based Information

\begin{tabular}{|c|c|}
\hline Question & Data \\
\hline \multicolumn{2}{|c|}{ How easy did you think it was to navigate in the web portal and use its features? } \\
\hline Very easy & $16(33)$ \\
\hline Pretty easy & $29(59)$ \\
\hline Quite difficult & $4(8)$ \\
\hline Very difficult & $1(2)$ \\
\hline \multicolumn{2}{|l|}{ Was content presented so that it was easy to understand? } \\
\hline Not at all & 0 \\
\hline To small extent & 0 \\
\hline To some extent & $8(16)$ \\
\hline To high extent & $35(71)$ \\
\hline To very high extent & $6(12)$ \\
\hline \multicolumn{2}{|l|}{ Did you experience technical problems with web portal? } \\
\hline Not at all & $20(41)$ \\
\hline A little & $12(25)$ \\
\hline A part & $7(14)$ \\
\hline Pretty much & $7(14)$ \\
\hline Very much & $3(6)$ \\
\hline \multicolumn{2}{|c|}{ What did you think about the timing of when you got access to web-based information? } \\
\hline Too early; it should have been presented closer to examination & 0 \\
\hline It was at right time & $43(88)$ \\
\hline Too late; I had wanted access to web-based information earlier & $6(12)$ \\
\hline \multicolumn{2}{|l|}{ How much use did you have for the slide show? } \\
\hline No use at all & $1(2)$ \\
\hline Little use & $17(35)$ \\
\hline Quite useful & $20(41)$ \\
\hline Very useful & $10(20)$ \\
\hline \multicolumn{2}{|l|}{ How much use did you have for the written text? } \\
\hline No use at all & $3(6)$ \\
\hline Little use & $15(31)$ \\
\hline Quite useful & $23(47)$ \\
\hline Very useful & $7(14)$ \\
\hline \multicolumn{2}{|l|}{ How much use did you have for the frequently-asked-questions module? } \\
\hline No use at all & $8(16)$ \\
\hline Little use & $25(51)$ \\
\hline Quite useful & $15(31)$ \\
\hline Very useful & 0 \\
\hline \multicolumn{2}{|l|}{ On the whole, how satisfied are you with the web-based information? } \\
\hline Very satisfied & $15(31)$ \\
\hline Mostly satisfied & $27(55)$ \\
\hline Neither satisfied nor dissatisfied & $6(12)$ \\
\hline Quite dissatisfied & 0 \\
\hline Very dissatisfied & 0 \\
\hline \multicolumn{2}{|c|}{ Would you recommend web-based information to someone who will undergo the same PET/CT examination as you? } \\
\hline Yes, absolutely & $28(57)$ \\
\hline Yes, I think so & $20(41)$ \\
\hline No, I do not think so & 0 \\
\hline No, absolutely not & 0 \\
\hline
\end{tabular}

Total $n=49$ ( $89 \%$ of those who used intervention). Data are number of patients followed by percentage in parentheses.

by many patients, regardless of age. This possibility was also confirmed by Katz et al. (16), who found that high age is not a predictor of nonuse of the Internet (16). A possible reason might instead be problems with navigating and using the web-based information, as was reported by 5 of the nonusers in the present study. Thus, the web-based information was probably not accessible to all patients. If the web-based information is introduced into clinical routine, a log-in will not be required, thus potentially reducing technical prob- lems. However, we suggest that good access to technical support be available if a feature such as web-based information is used in a trial and requires a log-in. Also, web-based information cannot replace personal interactions with the health staff but should be considered a way to provide patients with complementary information received in a place and at a time of their choice.

This study has several limitations. The study population was too small, and recruitment was terminated before an 


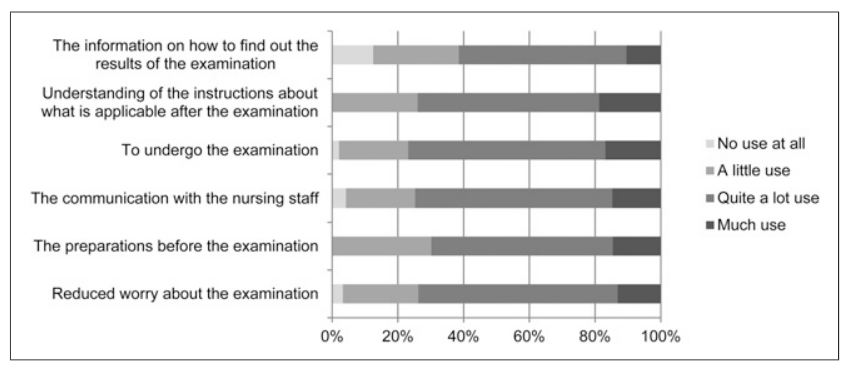

FIGURE 2. Answer to the question of how much benefit the patient received from web-based information in several respects $(n=49 / 54,89 \%)$.

adequate number of patients could be included, leading to insufficient power. The written information about the study was mailed by the nursing staff of the nuclear medicine department, who also assessed all referrals regarding patient eligibility for the study. Burdening the nursing staff with these tasks was not the best choice, especially given the unforeseen increase in the number of referrals to the department during the study period. It was not realistic to restart the recruitment because of a stressful work situation at the nuclear medicine department. Future studies should seek enough funding to allow hiring of research nurses dedicated to patient recruitment. Many patients were difficult to contact or unable to participate because they lacked Internet access, and many were scheduled for the examination too soon after they received notice of the examination date and were thereby excluded, making the time for inclusion longer than expected. Studies on larger populations with image quality as the primary outcome are suggested to achieve reliable results on the effects of webbased patient information on image quality. One possible way to increase the number of included patients may be to recruit patients in connection with their visit to their doctor, who makes the decision to refer them for the ${ }^{18} \mathrm{~F}-\mathrm{FDG}$ PET/ CT examination, since a personal meeting may increase their motivation to participate in the study. Helping patients access the Internet, such as by providing dedicated patient computers in hospitals and health centers or by lending tablets to patients in exchange for a deposit, is another possible way to increase recruitment. Some of the items in the questionnaire were not evaluated properly for validity and reliability. However, they have been used in previous studies $(4,10)$ on how patients experience PET/CT examinations, and the high response rate indicates that the questions were easy to understand. Because this is the first study on this topic, the results provide valuable knowledge that may be used to develop information routines to facilitate PET/CT examinations for all patients.

\section{CONCLUSION}

The effects of web-based information need to be investigated in larger samples of patients. Receiving improved information before an ${ }^{18} \mathrm{~F}$-FDG PET/CT examination may increase patients' knowledge and help them prepare for and undergo the examination. Improved image quality may also result, but this possibility needs to be investigated in trials using image quality as the primary outcome. The results of this study may be used to improve patient information and thereby patient care and to optimize the ${ }^{18} \mathrm{~F}-\mathrm{FDG}$ PET/CT procedure. However, future trials need to find strategies to ensure inclusion of sufficient participants and to provide them with good technical support if web-based information is used.

\section{DISCLOSURE}

No potential conflict of interest relevant to this article was reported.

\section{REFERENCES}

1. Boellaard R, Delgado-Bolton R, Oyen WJ, et al. FDG PET/CT: EANM procedure guidelines for tumour imaging: version 2.0. Eur J Nucl Med Mol Imaging. 2015;42:328-354.

2. Petersen H, Holdgaard PC, Madsen PH, et al. FDG PET/CT in cancer: comparison of actual use with literature-based recommendations. Eur J Nucl Med Mol Imaging. 2016;43:695-706.

3. Ziai P, Hayeri MR, Salei A, et al. Role of optimal quantification of FDG PET imaging in the clinical practice of radiology. Radiographics. 2016;36:481496.

4. Andersson C, Johansson B, Wassberg C, et al. Patient experience of an ${ }^{18}$ F-FDGPET/CT examination: need for improvements in patient care. J Radiol Nurs. 2015;34:100-108.

5. Abreu C, Grilo A, Lucena F, Carolino E. Oncological patient anxiety in imaging studies: the PET/CT example. J Cancer Educ. 2017;32:820-826.

6. Grilo A, Vieira L, Carolino E, et al. Anxiety in cancer patients during ${ }^{18} \mathrm{~F}-\mathrm{FDG}$ PET/CT low dose: a comparison of anxiety levels before and after imaging studies. Nurs Res Pract. 2017:3057495.

7. Bowden DJ, Yap LC, Sheppard DG. Is the internet a suitable patient resource for information on common radiological investigations? Radiology-related information on the internet. Acad Radiol. 2017;24:826-830.

8. Hansberry DR, Ayyaswami V, Sood A, Prabhu AV, Agarwal N, Deshmukh SP. Abdominal imaging and patient education resources: enhancing the radiologistpatient relationship through improved communication. Abdom Radiol (NY). 2017;42:1276-1280.

9. Lin ZC, Effken JA. Effects of a tailored web-based educational intervention on women's perceptions of and intentions to obtain mammography. J Clin Nurs. 2010;19:1261-1269.

10. Andersson C, Johansson B, Wassberg C, Johansson S, Sundin A, Ahlstrom H. Assessment of whether patients' knowledge, satisfaction, and experience regarding their ${ }^{18} \mathrm{~F}$-fluoride PET/CT examination affects image quality. $\mathrm{J} \mathrm{Nucl} \mathrm{Med}$ Technol. 2016;44:21-25.

11. Efron B. Forcing a sequential experiment to be balanced. Biometrika. 1971;58: 403-417.

12. Collins D. Pretesting survey instruments: an overview of cognitive methods. Qual Life Res. 2003;12:229-238.

13. Pettersen KI, Veenstra M, Guldvog B, Kolstad A. The patient experiences questionnaire: development, validity and reliability. Int J Qual Health Care. 2004;16: 453-463.

14. Ketelaars PJW, Buskes MHM, Bosgraaf RP, et al. The effect of video information on anxiety levels in women attending colposcopy: a randomized controlled trial. Acta Oncol. 2017;56:1728-1733.

15. Törnqvist E, Mansson A, Larsson EM, Hallstrom I. Impact of extended written information on patient anxiety and image motion artifacts during magnetic resonance imaging. Acta Radiol. 2006;47:474-480.

16. Katz JE, Roberge D, Coulombe G. The cancer patient's use and appreciation of the Internet and other modern means of communication. Technol Cancer Res Treat. 2014;13:477-484.

17. Freund O, Reychav I, McHaney R, Goland E, Azuri J. The ability of older adults to use customized online medical databases to improve their health-related knowledge. Int J Med Inform. 2017;102:1-11. 